
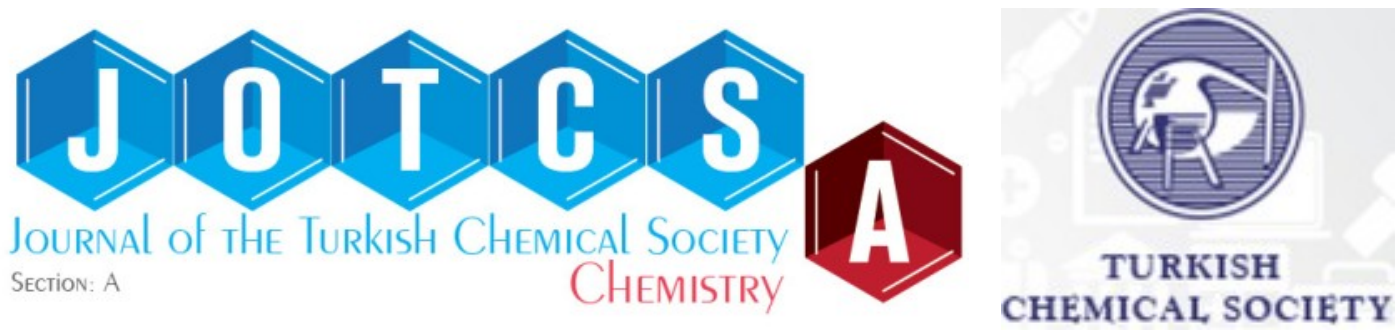

\title{
Hydrothermal Synthesis and Crystal Structure of Zn(II) Coordination Polymer with Rigid 4,4'-azobispyridine
}

\author{
Figen Arslan Biçer $M$
}

Department of Chemistry, Karabük University, TR-78050 Karabük, Turkey

Abstract: The new metal complex with phenylsuccinic acid $\left(\mathrm{H}_{2} \mathrm{psa}\right)$ and 4,4'-azobispyridine (4,4'-abpy), $\left\{\left[\mathrm{Zn}(\mathrm{psa})\left(\mathrm{H}_{2} \mathrm{O}\right)_{3}\left(\mu-4,4^{\prime}-\mathrm{abpy}\right)\right]\left(\mathrm{H}_{2} \mathrm{O}\right)\right\}_{n}(\mathbf{I})$, was synthesized by hydrothermal process. The structure of $\mathbf{I}$ has been characterized by IR spectra, elemental analysis, and single crystal X-ray diffraction. Single crystal X-ray analysis reveals that the psa ligand O-coordinated to the $\mathrm{Zn}$ (II) ion and distorted octahedral geometry of $\mathrm{Zn}(\mathrm{II})$ ion is completed by bridging $4,4^{\prime}$-abpy and three aqua ligands.

Keywords: Coordination polymers, 4,4'-azobispyridine, phenylsuccinic acid, Zn complexes.

Submitted: March 06, 2019. Accepted: October 11, 2019.

Cite this: Arslan Biçer F. Hydrothermal Synthesis and Crystal Structure of Zn(II) Coordination Polymer with Rigid 4,4'-azobispyridine. JOTCSA. 2020;7(1):43-8.

DOI: https://doi.org/10.18596/jotcsa.536258.

*Corresponding author. E-mail: farslan@karabuk.edu.tr.

\section{INTRODUCTION}

Although it was stated that coordination polymers had emerged in 1960s, it has attracted attention via leading reports on the findings of the porous structures and associated functionalities since 1990s (1). Since the past decade, the interest in searching for the coordination polymers has aroused profoundly for the immediate increase in the publication ratio and number about them. Coordination polymers which are known as $1 D, 2 D$ and $3 D$ are considered structurally interesting, especially 1D polymers have intruguing electrical, optical and magnetic properties (2). For 1D chains, selfassembly of metal ions that have specific directionality and functionality with organic ligands that have appropriate functional groups is relatively simple; however, this simplicity leads to corporate structural features at the metal centers or in the backbone of the bridging ligands (3). We have studied on the metalphenylsuccinate-azobispyridine system, in which 4,4-azobispyridine (4,4'-abpy) has a structure with a $\pi$ conjugated system and two coordinatively active nitrogen atoms in which pyridine nitrogens are more basic and are more accessible for polynuclear arrangements for steric reasons (4-12). Furthermore, azobispyridine complexes are used as electrooptical devices for reversible data storage, in indicators, therapeutic and drug delivery agents, and photochemical switches. Even if $\mathrm{H}_{2}$ psa displays coordination capabilities of the two carboxylate groups and an amazing phenyl ring side group, that is presumed to modulate and affect the orientation relationship (13), in fact there are still few studies on $\mathrm{H}_{2}$ psa. In addition, more interesting coordination polymers can be obtained through enforcing it as a configurationally asymmetric bridging ligand. The aim of this work was to prepare new coordination polymers of phenylsuccinate complexes of $\mathrm{Zn}$ (II) metal ion with 4,4'azobispyridine by hydrothermally prosess, and to analyze their structural and spectroscopic characteristics using single crystal X-ray diffraction and IR technique. 


\section{EXPERIMENTAL}

\section{Materials and measurements}

All chemicals used were of analytical reagent quality. The 4,4'-abpy ligand was synthesized by oxidation of the 4-aminopyridine with $\mathrm{NaOCl}$ according to literature (Kirpal-Reiter method) (15). Elemental analysis was performed by standard methods at IBTAM (İnönü University Scientific Research Centre). The IR spectrum was recorded on a Bruker Tensor 27 FT/IR spectrophotometer using $\mathrm{KBr}$ pellets and operating at $4000-400 \mathrm{~cm}^{-1}$. The X-ray diffraction data of the complex were collected with a Bruker Kappa Apex2duo diffractometer. The structures were solved and refined by fullmatrix least-squares techniques on $\mathrm{F}^{2}$ by using the SHELXT-2015 program (16). The absorption corrections were done by the multiscan technique. All non-hydrogen atoms were refined anisotropically. All non-water hydrogen atoms were included in the refinement process by using a riding model.

\section{Synthesis of the complex}

\section{$\mathrm{Zn}(\mathrm{Ac})_{2} .2 \mathrm{H}_{2} \mathrm{O} \quad(24 \mathrm{mg}, 0.11 \mathrm{mmol})$,} phenylsuccinic acid (21 $\mathrm{mg}, 0.11 \mathrm{mmol}$ ) and 4,4'-abpy ( $20 \mathrm{mg}, 0.11 \mathrm{mmol}$ ) were placed into $10 \mathrm{~mL}$ of distilled $\mathrm{H}_{2} \mathrm{O}$ in a pyrex bottle. The bottle was sealed and heated in an oven at 120 ${ }^{\circ} \mathrm{C}$ for $72 \mathrm{~h}$, and then cooled slowly to $25^{\circ} \mathrm{C}$. Red blocks of 1 (33 mg, 58\%) were isolated after washing with distilled water and acetone, and finally drying in air. Anal. Calc. for $\mathrm{C}_{20} \mathrm{H}_{24} \mathrm{~N}_{4} \mathrm{O}_{8} \mathrm{Zn}: \mathrm{C}$ ，46.75; $\mathrm{H}, 4.71 ; \mathrm{N}, 10.90$. Found: C, 47.09; H, 4.27; N, 10.12\%. IR $\left(\mathrm{cm}^{-1}\right)$ : $3505(\mathrm{mb}), 3433(\mathrm{~m}), 3104(\mathrm{w}), 3053(\mathrm{w})$, 2976 (w), 2911 (w), 1611 (s), 1583 (s), 1491 $(\mathrm{m}), 1423(\mathrm{~s}), 1367(\mathrm{~s}), 1226(\mathrm{~m}), 1168(\mathrm{~m})$, $1051(\mathrm{~m}), 1026(\mathrm{~m}), 846(\mathrm{~s}), 741(\mathrm{~m}), 704(\mathrm{~m})$, $680(\mathrm{~s}), 566(\mathrm{~m}), 526(\mathrm{w})$.

\section{RESULT AND DISCUSSION}

\section{Vibrational Analysis}

The elemental analysis results and selected IR data are consisted with assigned formulation. The observation of the IR spectrum of $\mathbf{I}$ was performed by considering the most important internal vibrations of carboxylate, phenyl and azo groups, and water molecules.

The bands of stretching vibrations $v(\mathrm{O}-\mathrm{H})$ were found at $3433 \mathrm{~cm}^{-1}$ for compound $\mathbf{I}$, indicating that the water molecules exist within the structures. Because of the $\mathrm{v}(\mathrm{CH})$ vibrations of aromatic and aliphatic groups, the relatively weak bands are above and below $3000 \mathrm{~cm}^{-1}$, respectively. The absorption bands of the carbonyl groups of $\mathbf{I}$ in which psa is Ocoordinated (monodentate) are found out as strong bands at $1583 \mathrm{~cm}^{-1}$ and $1611 \mathrm{~cm}^{-1}$ respectively $(14,17)$. It is considered that intraand intermolecular hydrogen bonding interactions involving the carbonyl group shift this band to higher frequencies. The bands of symmetric $v_{s}(\mathrm{COO})$ stretch was found at 1367 $\mathrm{cm}^{-1}$ for $\mathbf{I}$. The values of $\Delta v\left[v_{\mathrm{as}}(\mathrm{COO})-v_{\mathrm{s}}(\mathrm{COO})\right]$ in the the complex (more than 200) fall within the range for a vibrational mode associated with a monodentate ligand (18). The bands centered around $1423 \mathrm{~cm}^{-1}$ are assigned to the $\mathrm{N}=\mathrm{N}$ vibrations of the 4,4'-abpy ligand. $\quad \mathrm{C}=\mathrm{N}$ vibrations of 4,4'-abpy appear at ca. $1583 \mathrm{~cm}^{-1}$.

\section{Crystal Structure}

The crystal data, experimental details and refinement details of complex are given in Table 1. Selected bond distances, angles and hydrogen band geometries are listed in Tables 2-3, respectively. 


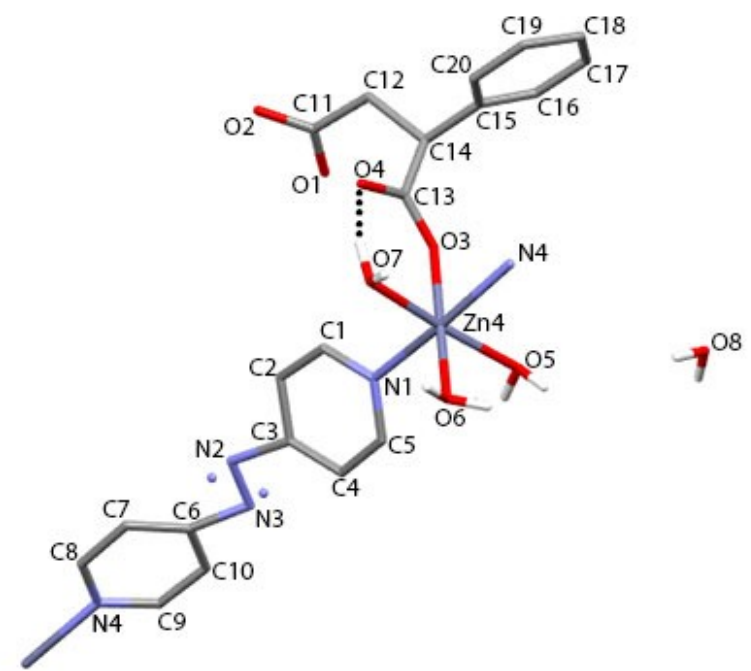

Figure 1. The crystal structure of I displaying the atom-labelling scheme. Table 1. Crystal data and structure refinement parameters for complex $\mathbf{I}$.

\begin{tabular}{|c|c|}
\hline Crystal data & 1 \\
\hline Empirical formula & $\mathrm{C}_{20} \mathrm{H}_{24} \mathrm{~N}_{4} \mathrm{O}_{8} \mathrm{Zn}$ \\
\hline Formula weight & 513.83 \\
\hline Crystal system & Monoclinic \\
\hline $\mathrm{T}(\mathrm{K})$ & $100(2)$ \\
\hline$\lambda(\AA)$ & 0.71073 \\
\hline Space group & $\mathrm{P} 2_{1} / \mathrm{n}$ \\
\hline $\mathrm{a}(\AA)$ & $12.676(4)$ \\
\hline $\mathrm{b}(\AA)$ & $9.681(2)$ \\
\hline$c(\AA)$ & $19.455(6)$ \\
\hline$\beta\left({ }^{0}\right)$ & $108.716(9)$ \\
\hline$V\left(\AA^{3}\right)$ & $2261.3(11)$ \\
\hline Z & 4 \\
\hline$D_{c}\left(\mathrm{~g} \mathrm{~cm}^{-3}\right)$ & 1.5091 \\
\hline$\mu\left(\mathrm{mm}^{-1}\right)$ & 1.14 \\
\hline Measured ref. & 75543 \\
\hline Independent ref. & 5634 \\
\hline$\theta$ Range $\left({ }^{\circ}\right)$ & $0.963-1.00$ \\
\hline Crystal size (mm) & $0.15 \times 0.11 \times 0.1$ \\
\hline
\end{tabular}




$\begin{array}{ll}\mathrm{R}_{\text {int }} & 0.088 \\ \mathrm{~S} & 1.05 \\ R, R w[I>2 \sigma(I)] & 0.067,0.189 \\ \Delta \rho_{\max } / \Delta \rho_{\min }\left(\mathrm{e}^{-3}\right) & 2.5, /-0.89\end{array}$

Table 2 Selected bond distances and angles for complex $\mathbf{I}\left(\AA,{ }^{\circ}\right)$

\begin{tabular}{llll}
\hline $\begin{array}{l}\text { Bond } \\
\text { distance }\end{array}$ & $\AA$ & $\begin{array}{l}\text { Bond } \\
\text { distance }\end{array}$ & $\AA$ \\
\hline Zn4-O5 & 2.07 & Zn4-O6 & 2.110 \\
& 4 & & \\
Zn4-N1 & 2.14 & Zn4-O3 & 2.188 \\
& 8 & & \\
\hline Bond angle & $\circ$ & Bond angle & $\circ$ \\
\hline O5-Zn4-N1 & 95 & O6-Zn4-N1 & 106 \\
O7-Zn4-O3 & 92.6 & O6-Zn4-O3 & $\begin{array}{l}177.6 \\
6\end{array}$ \\
\hline
\end{tabular}

According to the X-ray structural analysis, I crystallized in the monoclinic space group of $P 21 / n$. The asymmetric unit comprises of a $\mathrm{Zn}$ (II) atom, one half of the abpy, one PSA ligand as monodentate, three aqua ligands and one the lattice water molecule. (Figure 1.) The zinc settles with an octahedral geometry with the PSA units and three aqua ligands on the equatorial plane and the axial sites are filled by two symmetry-related $\mu$-abpy ligands $(\mathrm{Zn}-\mathrm{N}=$ 2.148(3) $A^{\circ}$ ) and subsequently, together with the the bridging abpy ligands, compose a onedimensional coordination polymer. (Figure 2.).

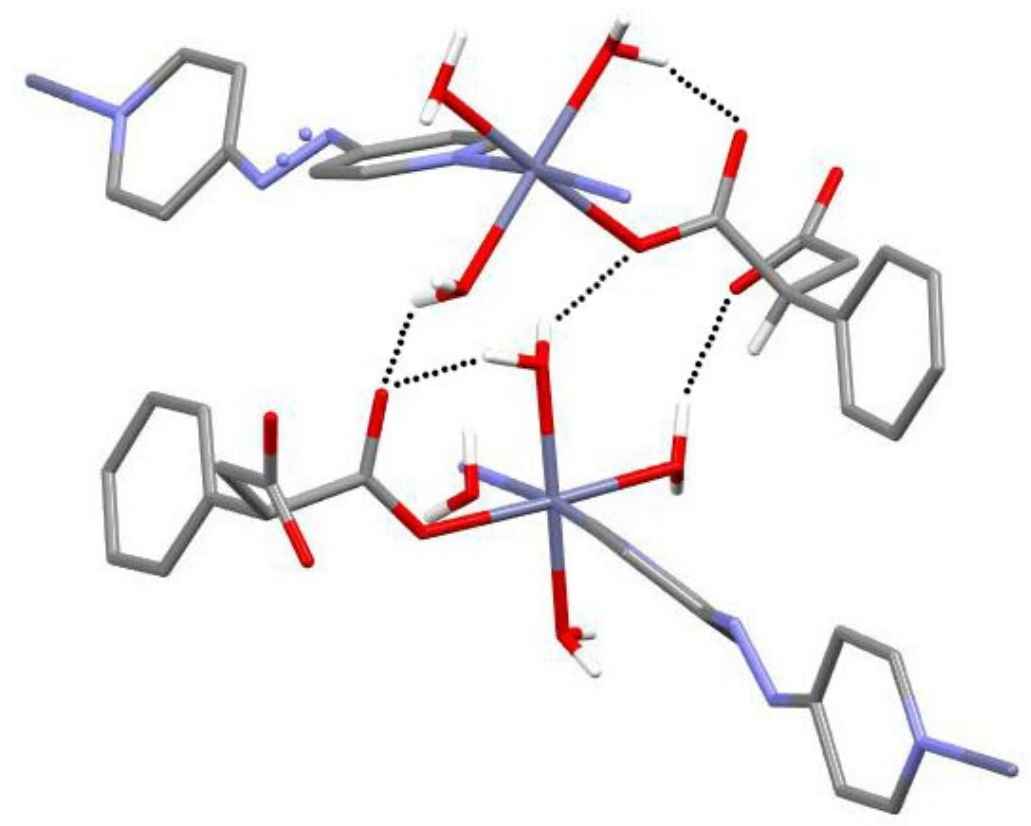

Figure 2. Hydrogen-bonding for $\mathbf{I}$

Contrary to expectations, PSA ligand is coordinated monodentate via carboxylate oxygen. The azo $\mathrm{N}$ atoms of 4,4'-azobispyridine was found to be distorted, probably due to unresolved disorder. 
Table 3. Hydrogen-bond parameters for complex $\mathbf{I}(\AA, 0)$

\begin{tabular}{|c|c|c|c|c|}
\hline D-H'..A & $\mathbf{D}-\mathbf{H}$ & $\begin{array}{l}H \cdots \\
A\end{array}$ & D...A & $D-H \cdots A$ \\
\hline O5-H5A $\cdots$ O 4 & 0.87 & 2.06 & $2.795(4)$ & 141.4 \\
\hline $\mathrm{O} 5-\mathrm{H} 5 \mathrm{~B} \cdots \mathrm{O} 2^{\mathrm{i}}$ & 0.87 & 1.87 & $2.649(5)$ & 148.8 \\
\hline $\mathrm{O} 7-\mathrm{H} 7 \mathrm{~A} \cdots \mathrm{O} 4^{\mathrm{ii}}$ & 0.87 & 1.82 & $2.628(4)$ & 153.7 \\
\hline $\mathrm{O} 6-\mathrm{H} 6 \mathrm{~A} \cdots \mathrm{O} 1^{\mathrm{iii}}$ & 0.87 & 1.91 & $2.744(5)$ & 160.4 \\
\hline $\mathrm{O} 6-\mathrm{H} 6 \mathrm{~B} \cdots \mathrm{O} 1^{\mathrm{i}}$ & 0.87 & 1.95 & $2.815(5)$ & 169.0 \\
\hline $\mathrm{O} 8-\mathrm{H} 8 \mathrm{~B} \cdots \mathrm{O} 2^{\mathrm{i}}$ & 0.85 & 1.96 & $2.803(9)$ & 172.5 \\
\hline
\end{tabular}

Symmetry codes: (i) $-x+\overline{1,-y+1,-z+1 \text {; (ii) }-x+1 / 2, y-1 / 2,-z+1 / 2 \text {; (iii) } x, y}-1, z$.

The crystals are stabilized by intra- and intermolecular hydrogen bonding. As shown in Figure 2 , adjacent complex units are connected by $\mathrm{O5-}$ $\mathrm{H} 5 \mathrm{~A} \cdots \mathrm{O} 4, \mathrm{O} 5-\mathrm{H} 5 \mathrm{~B} \cdots \mathrm{O} 2^{\mathrm{i}}$, O6- $\mathrm{H} 6 \mathrm{~A} \cdots \mathrm{O} 1^{\mathrm{iii}}$ and 08 - $\mathrm{H} 8 \mathrm{~B} \cdots \mathrm{O} 2^{i}$ hydrogen bonding between aqua and carboxy oxygen atom of phenylsuccinate ligands. 1D coordinasyon polymer units are connected by $\mathrm{O} 5-\mathrm{H} 5 \mathrm{~B} \cdots \mathrm{O} 2^{\mathrm{i}}$ and $\mathrm{O} 6-\mathrm{H} 6 \mathrm{~B} \cdots \mathrm{O} 1^{\mathrm{i}}$ hidrogen bonds between aqua and carboxy oxygen atom of phenylsuccinate ligands (Figure 3).

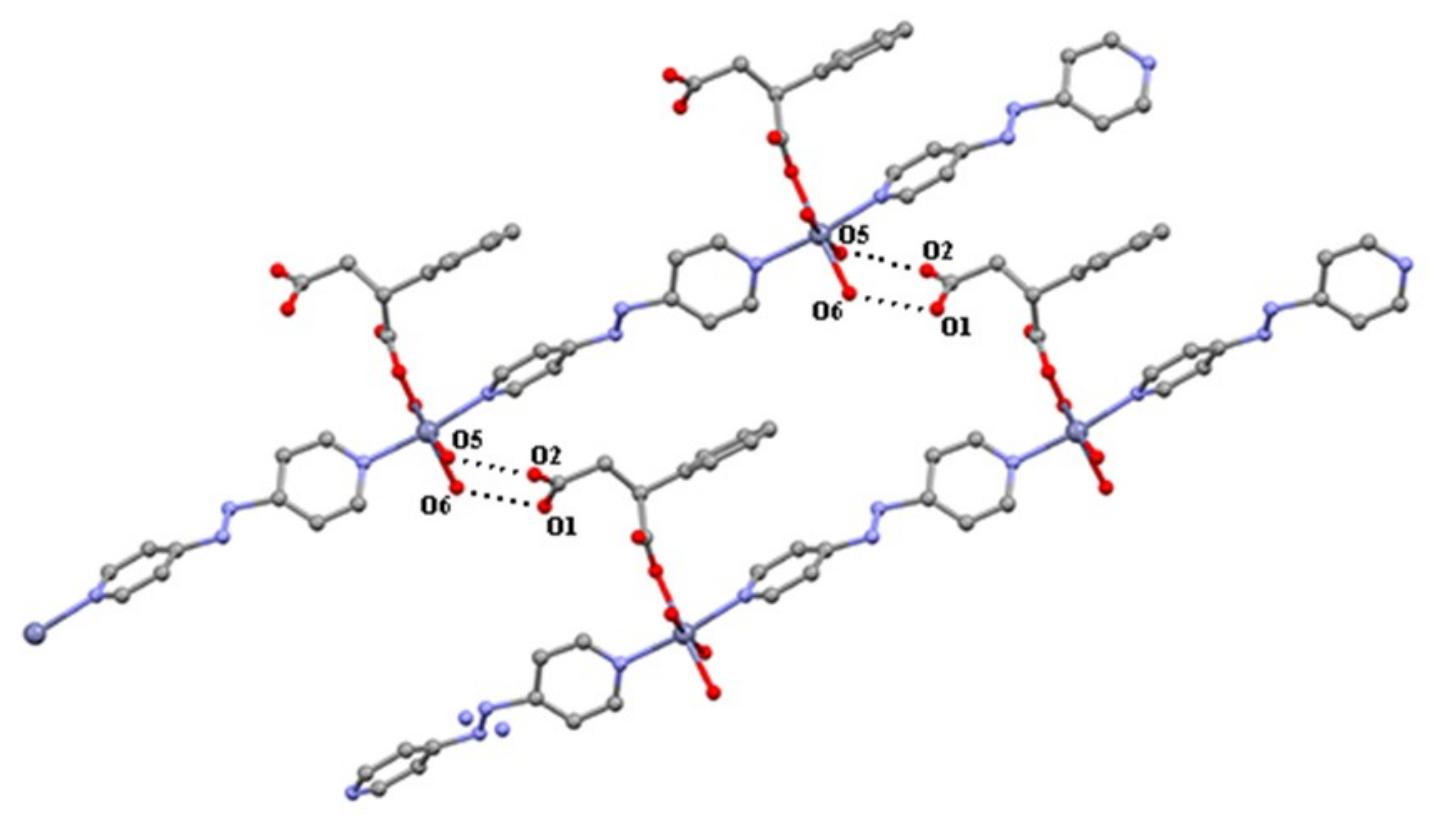

Figure 3. View of the infinite 1D chain structure of $\mathbf{I}$.

\section{CONCLUSIONS}

As a summary, the title coordination polymer, $\left\{\left[\mathrm{Zn}(\mathrm{psa})\left(\mathrm{H}_{2} \mathrm{O}\right)_{3}(\mu-4,4 \text {-abpy })\right]\left(\mathrm{H}_{2} \mathrm{O}\right)\right\}_{\mathrm{n}}$, has been hydrothermally prepared by utilizing phenylsuccinic acid and 4,4'-azobispyridine ligands. X-ray structural analysis and IR data display that the complex compose a onedimensional coordination polymer together with the the bridging abpy ligands. It is examined that phenylsuccinate-azobispyridine system should be a good candidate to achieve the desired multifunctionalities in coordination polymer.

\section{ACKNOWLEDGEMENTS}

This work has been supported by Karabuk University, Scientific Research Unit (KBÜBAP-18YL-060). Author is thankful to Prof. Dr. O. Z. Yeşilel, for crystallographic data analysis.

\section{REFERENCES}

1. Zhang J-P, and Chen X-M. Metal-Organic Frameworks for Second-Order Nonlinear Optics. Struct Bond. 2014; 157:1-26. 
2. Leong $W L$, and Vittal JJ. One-Dimensional Coordination Polymers: Complexity and Diversity in Structures, Properties, and Applications. Chem. Rev. 2011; 111:688-764.

3. Janiak C, and Vieth JK. MOFs, MILs and more: concepts, properties and applications for porous coordination networks (PCNs). New J. Chem., 2010; 34:2366-2388.

4. Li B, Liu H, Xu Y, Chen J, Wang H, Xu Z. Synthesis and crystal structure of two cobalt complexes: [Co2(4,4'-azpy)5(H2O)6] [ClO4]4-(H2O)10:(4,4'-azpy)4 with a novel twodimensional large rectangle organic-inorganic hybrid network and one-dimensional chain complex $\left\{\left[\mathrm{Co}\left(3,3^{\prime}\right.\right.\right.$-azpy $\left.)(\mathrm{H} 2 \mathrm{O}) 4\right][\mathrm{ClO} 4] 2 \cdot\left[3,3^{\prime}-\right.$ azpy]3\}n (4,4'-azpy4,4'-azobispyridine, 3,3'azpy3,3'-azobispyridine).J. Mol. Struct. 2001; 597:21-30.

5. Dey R, Ghoshal D. Syntheses and characterization of two supramolecular selfassembled $\mathrm{Mn}$ (II) compounds using trans 4,4'azobispyridine as a bridging ligand: Effect of $\Pi-\Pi$ interactions in the formation of a solid-state structure. Polyhedron. 2012; 34:24-30.

6. Theilmann O, Saak W, Haase D, Beckhaus R. Reactions of Low-Valent Titanocene(II) Fragments with trans-4,4'-Azobispyridine $(\mathrm{RN}=\mathrm{NR}, \mathrm{R}=\mathrm{C} 5 \mathrm{H} 4 \mathrm{~N})$ : Formation of Tetranuclear Molecular Squares by trans-cis Isomerization. Organometallics. 2009; 28:2799-2807.

7. Arslan F. Synthesis, crystal structure and spectrothermal characterization of zinc(II) salicylato complex with 2,2'-azobispyridine, $[\mathrm{Zn}(\mathrm{Hsal}) 2(\mathrm{H} 2 \mathrm{O})(\mathrm{abpy})] \cdot \mathrm{H} 2 \mathrm{O}$. Dyes and Pigments. 2007; 75:521-525.

8. Zhuang Z, Cheng J, Wang X, Yin Y, Chen G, Zhao $B$, Zhang $H$, Zhang $G$. Spectroscopy of 4,4'-azopyridine by density functional theory and surface-enhanced Raman scattering. J. Mol. Struct. 2006; 794:77-82.

9. Noro S, Kitagawa S, Nakamura T, Wada T. Synthesis and Crystallographic Characterization of Low-Dimensional and Porous Coordination Compounds Capable of Supramolecular Aromatic Interaction Using the 4,4'-Azobis(pyridine) Ligand. Inorg. Chem. 2005; 44:3960-3971.

10. Zhuang Z, Shanga X, Wanga X, Ruana W, Zhaoa B. Density functional theory study on surface-enhanced Raman scattering of 4,4'azopyridine on silver. Spectrochim. Acta Part A. 2009; 72:954-958.
11. Niu $Y$, Song $Y$, Hou $H$, Zhu $Y$. The syntheses, crystal structures and optical limiting effects of HgI2 adduct polymers bridged by bipyridylbased ligands. Inorganica Chimica Acta. 2003; 355:151-156.

12. Launay J, Tourrel-Pagis M, Lipskier J, Marvaud V, Joachim C. Control of intramolecular electron transfer by a chemical reaction. The 4,4'-azopyridine/1,2-bis(4-pyridyl)hydrazine system. Inorg. Chem. 1991; 30:1033-1038.

13. Thuery $P$. Uranyl-organic bilayer assemblies with flexible aromatic di-, tri- and tetracarboxylic acids. CrystEngComm, 2009, 11:1081-1088.

14. Hu S, Zhang $P$, Yu F-Y, Lin D-R, Chen $M-X$. Constructions of two photoluminescent 3D coordination polymers comprising of hydroxidebridged cadmium chain and polynuclear cadmium macrocycle using phenylsuccinic acid. J. Mol. Struct. 2013; 1051:72-77.

15. Baldwin D A, Lever A B $P$, Parish $R$ V. Complexes of 2,2'-azopyridine with iron(II), cobalt(II), nickel(II), copper(I), and copper(II). Infrared study. Inorg. Chem. 1969; 8(1):107115.

16. Sheldrick G, SHELXT - Integrated spacegroup and crystal-structure determination Acta Crystallogr. Sect. A. 2015; 71:3-8

17. Gomez G E, Bernini M C, Brusau E V, Narda G E, Vega D, Kaczmarek A M, Van Deun R, Nazzarro M. Layered exfoliable crystalline materials based on Sm-, Eu- and Eu/Gd-2phenylsuccinate frameworks. Crystal structure, topology and luminescence properties. Dalton Trans., 2015; 44:3417-3429.

18. Wang J, Zhang $Y$, Liu X-Q, Xiao J, Zhou $H$, Yuan A-H. Two $\mathrm{Zn}$ (II) and $\mathrm{Co}$ (II) compounds with dicarboxylates and curved 4,4'-azopyridine ligands: Syntheses, crystal structures and gas sorption properties. Microporous and Mesoporous Materials. 2012; 159:100-104. 